Portland State University

PDXScholar

1990

\title{
The use of phonological process assessment for differentiating developmental apraxia of speech from functional articulation disorders
}

Kathryn DeArmond

Portland State University

Follow this and additional works at: https://pdxscholar.library.pdx.edu/open_access_etds

Part of the Speech and Hearing Science Commons

Let us know how access to this document benefits you.

Recommended Citation

DeArmond, Kathryn, "The use of phonological process assessment for differentiating developmental apraxia of speech from functional articulation disorders" (1990). Dissertations and Theses. Paper 3980. https://doi.org/10.15760/etd.5861

This Thesis is brought to you for free and open access. It has been accepted for inclusion in Dissertations and Theses by an authorized administrator of PDXScholar. Please contact us if we can make this document more accessible: pdxscholar@pdx.edu. 
AN ABSTRACT OF THE THESIS OF Kathryn DeArmond for the Master of Science in Speech Communication: Speech and Hearing Sciences presented August 9, 1990.

Title: The Use of Phonological Process Assessment for Differentiating Developmental Apraxia of Speech from Functional Articulation Disorders.

APPROVED BY THE MEMBERS OF THE THESIS COMMITTEE:
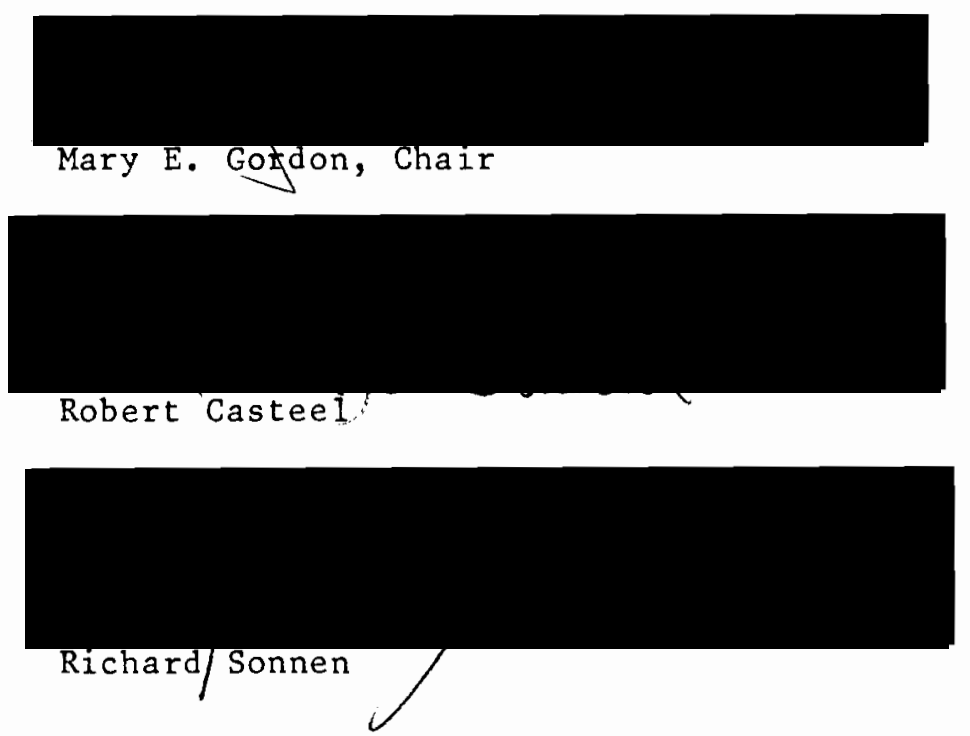

Focus has turned from emphasis on phonetic sound errors to phonologic rule systems in the study of articulation disorders. The current theory proposes that the phonological disorders which children experience are controlled by higher levels in the brain than those that control the motor functioning of the brain. The purpose of the present study was to compare the use of phonological processes 
by a group of school-age children with moderate to severe multiple articulation disorders (MAD) with developmental apraxia of speech (DAS) to the phonological processes used by those without developmental apraxia of speech. For the purposes of this study, those without DAS were classified as functional articulation disorder (FAD).

The 18 subjects, ages 5.9 to 12.1 years, presenting with multiple articulation disorders, were chosen from the greater Portland, Oregon, metropolitan area. To qualify for the study, all subjects did not display mental retardation, hearing impairment, visual impairment, social-emotional impairment, multiple handicaps, or other impairments which could interfere with speech sound production. One group of ten children presented with DAS as determined by scores on the STDAS (Blakeley, 1980) and were classified as severe by scores on the AAPS-R (Fudala, 1982). The other group of eight subjects presented without DAS and were labeled FAD. Of the eight subjects, four were determined to have severe articulation disorders and the other four were determined to have moderate articulation disorder through AAPS-R. The APPS-R/CAPP (Hodson, 1986; 1985) was administered and the percentage of use of phonological processes, phonological deviancy score, and average use of the ten basic phonological processes were calculated. Other processes which have been suggested by the literature to be indicative of DAS, e.g., voicing errors and metathesis, were also assessed and analyzed by hand.

A two-tailed $\underline{t}$-test for independent means was used to determine if a statistically significant difference existed between the DAS and 
FAD subjects. A statistically significant difference $(p<.05)$ was found between the two groups for average of phonological process use and phonological deviancy scores. In addition, use of the phonological processes of consonant sequence, stridents, velars, liquid (1), glides, and assimilations were found to be significantly different between the two groups with the DAS group using these processes more than the FAD group. A significant difference between the two groups was not found for syllable reduction, prevocalic singleton, postrocalic singleton, liquid $(r)$, nasals, metathesis and voicing errors. Although three factors, (a) the small number of subjects, (b) the age range, (c) the use of the STDAS to establish the DAS group, must be considered when drawing conclusions from the data, the results indicate a significant difference in the use of phonological processes by subjects with FAD and those with DAS. The results suggest that more research is needed in the area of phonological process use by school-age children with MAD, with and without DAS. Treatment for children with DAS in addition to MAD may benefit from a phonological process approach in combination with a motor programming approach. 
THE USE OF PHONOLOGICAL PROCESS ASSESSMENT FOR DIFFERENTIATING DEVELOPMENTAL APRAXIA OF SPEECH FROM FUNCTIONAL ARTICULATION DISORDERS

$$
\text { by }
$$

KATHRYN DEARMOND

A thesis submitted in partial fulfillment of the requirements for the degree of

\author{
MASTER OF SCIENCE \\ in \\ SPEECH COMMUNICATION : \\ SPEECH AND HEARING SCIENCES
}

Portland State University

1990 
TO THE OFFICE OF GRADUATE STUDIES:

The members of the Committee approve the thesis of Kathryn DeArmond presented August 9, 1990.

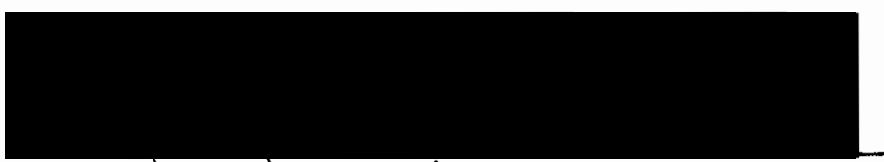

Mary E. Gordpn, Chair

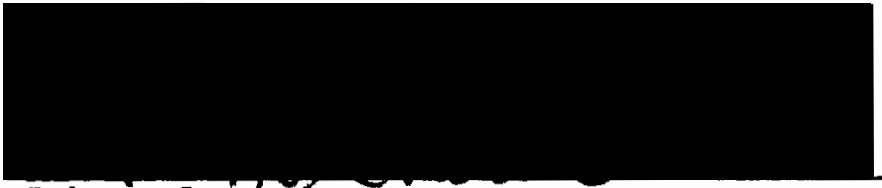

Robert Casteel
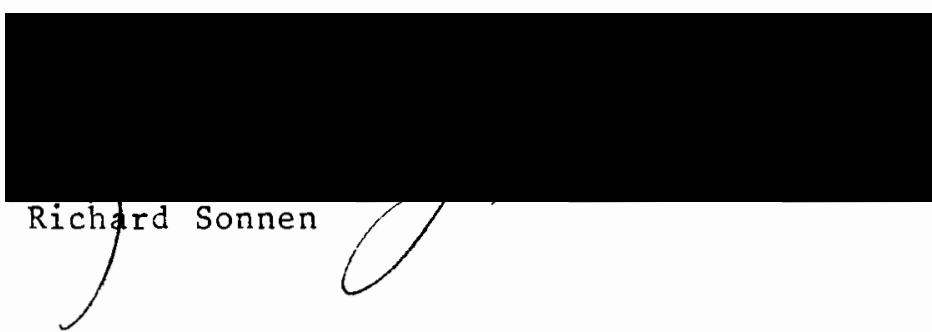

APPROVED :
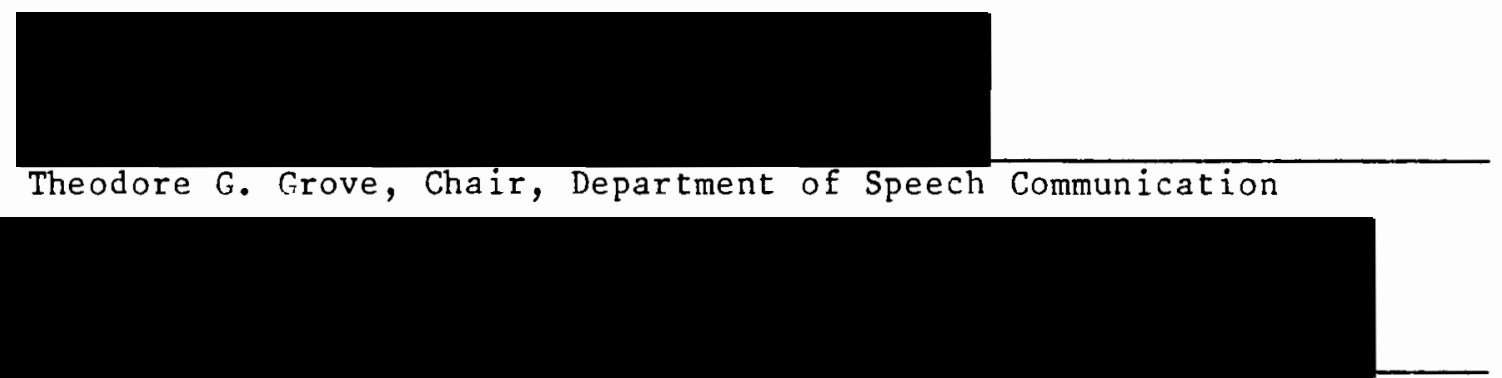

C. William savery, Interim vice provost fof Graduate studies and Research 


\section{ACKNOWLEDGEMENTS}

I would like to thank the members of my committee:

$$
\begin{aligned}
& \text { Mary E. Gordon } \\
& \text { Robert Castee1 } \\
& \text { Richard Sonnen }
\end{aligned}
$$

for their help and encouragement. In addition, I would like to thank my advisor, Mary E. Gordon, for her expert guidance. I also want to thank Barbara Haberman and Gail Woodward, fellow students, for their support .

Finally, I would like to thank my parents, Helen and Robert Ellingson, and my children, Brent, Tommy, and Lisa for their love, unending support, encouragement, and patience. 
TABLE OF CONTENTS

PAGE

ACKNOWLEDGEMENTS

i i i

LIST OF TABLES

vi

CHAPTE R

I INTRODUCTION AND STATEMENT OF PURPOSE . . . . . . . . 1

Introduction ............... 1

Statement of Purpose . . . . . . . . . 3

Definition of Terms . . . . . . . . . . 3

II REVIEW OF THE LITERATURE . . . . . . . . . . . . . 5

Multiple Articulation Disorders... . . . . 5

Developmental Apraxia of Speech . . . . . . 6

Differentiating FAD From DAS . . . . . . . . 7

Approaches to Remediation of FAD and DAS . . . 11

Phonetic Vs. Phonologic Errors . . . . . . 13

Use of Phonological Processes in Multiple Articulation Disorders . . . . . . . . 15

Assessment Instruments

II METHODS . . . . . . . . . . . . . . . . 19

Subjects . . . . . . . . . . . . . 19

Instrumentation . . . . . . . . . 20 
Procedures . . . . . . . . . . . . .

Experimental Procedures

Reliability

Data Scoring and Analysis... . . . . . 22

IV RESULTS AND DISCUSSION . . . . . . . . . . . 23

Results................... 23

Discussion . . . . . . . . . . . 32

V SUMMARY AND IMPLICATIONS . . . . . . . . . . . 35

Summary . . . . . . . . . . . 35

Implications . . . . . . . . . . . 37

Research

Clinical

REFERENCES

APPENDICES

A DEFINITIONS OF THE PHONOLOGICAL PROCESSES USED IN THE ASSESSMENT OF PHONOLOGICAL PROCESSES (HodsOn,

1986)

B CONSENT FORM .................... 45

C APP-R TEST FORM . . . . . . . . . . . . . 47

D APP-R ANALYSIS FORM . . . . . . . . . . . . 49

E CAPP FORM . . . . . . . . . . . . . . . 52 


\section{LIST OF TABLES}

TAB LE

PAGE

I Characteristics of DAS Reported in the Literature . . 8

II Average of Phonlogical Process Use By FAD and

DAS Subjects . . . . . . . . . . . . . 24

II $\underline{t}$-Test Results on Average of Phonological Process

Usage Scores for FAD and DAS Subjects . . . . 25

IV ANCOVA Results on Average of Phonological Process

Usage Scores for FAD and DAS Subjects . . . . . 25

$V \quad t-T e s t$ Results on Phonological Deviancy Scores for

FAD and DAS Subjects...... . . . . . 26

VI ANCOVA for Adjusted Group Means on Phonological

Deviancy Scores for FAD and DAS Groups . . . . 27

VII Mean Percentage of Occurrence and $\underline{t}$-Test Results for

Omissions for FAD and DAS Groups . . . . . . 28

VIII Mean Percentage of Occurrence and $\underline{t}$-Test Results for

Class Deficiencies for FAD and DAS Groups . . . 29

IX Mean Percentage of Occurrence and $\underline{t}$-Test Results for

Phonemic Substitutions, Assimilations, and

Voicing Alterations for FAD and DAS Groups . . . 30

$X$ ANCOVA for Group Means of Pattern Deviations for FAD

and DAS Groups . . . . . . . . . . . . 31 
CHAPTER I

INTRODUCTION AND STATEMENT OF PURPOSE

\section{INTRODUCTION}

Many children of preschool and school age display multiple articulation disorders (MAD) or many articulation errors. Some of these children use phonological process patterns beyond the expected age level for these patterns to disappear. The study of the use of these processes may provide information about a child's deviant speech and the type of disorder. It has been hypothesized that some of these children will present with a motor disorder while others will present with a linguistic disorder. It is important to differentiate between motor and linguistic disorders because different treatment approaches seemingly are required for the two types of disorders. Children's use of phonological processes may supply information leading to the separation of MAD into subgroups such as developmental apraxia of speech (DAS) and functional articulation disorders (FAD). The use of phonological process assessment could be a significant factor for determining which treatment approach to implement.

Little is known about the use of phonological processes by children with DAS. In fact, the clinical disorder of DAS has not been clearly described and therefore is difficult for speech-language clinicians to diagnose as well as to treat. DAS has been defined as 
a neurological disorder characterized by motor programming and execution difficulties for voluntary production of speech (Abbs \& Rosenbek, 1986 ; Haynes, 1985 ; Jaffe, 1984; Morley \& Fox, 1969 ; Nelson, 1989; Yoss \& Darley, 1974a). General1y, the impairment is considered to be in the deliberate, voluntary production of speech. The characteristic most apparent to clinicians is resistance to treatment using traditional articulation treatment procedures. The difficulty in assessment and treatment of this disorder continues to frustrate clinicians.

The phonological process approach is being used successfully in the assessment and treatment of some children with MAD. However, clinicians, after a period of traditional treatment, have reported some children with MAD not responding to that treatment. These children are often suspected of also presenting with the motor programming deficiencies attributed to DAS.

The Assessment of Phonological Processes--Revised (APPR-R) (Hodson, 1986) assesses error production in six areas: omissions, class deficiencies, phonemic substitutions, assimilations, voicing alterations, and place shifts. By administering this instrument to children with FAD and DAS, new information may be gained on the performance of children with these disorders. It would also suggest appropriate treatment for those individuals. The two groups could demonstrate separate use of processes, similar use of processes or use of processes distributed over a continuum. If there is no difference between the performance of children with FAD and those with 
DAS, it would indicate that the instrument is not appropriate to differentiate between the two groups.

\section{STATEMENT OF PURPOSE}

The purpose of the present study is to determine the percentage of use of phonological processes in a group of children with moderate to severe articulation disorders, differentiating use of phonological processes by those with DAS from use of processes by those with FAD.

The study proposes to answer the following research questions:

(1) Is there a significant difference in the average use of phonological processes by children with DAS and those with FAD?

(2) Is there a significant difference in phonological processes used by children with DAS and those with FAD?

The null hypothesis for this research is stated as: elementary school-age children diagnosed as presenting moderate to severe FAD do not demonstrate significant differences in properties and types of speech sound errors than children with DAS when assessed using a standardized phonological process test and analysis.

\section{DEFINITION OF TERMS}

The following definitions were used throughout the study. Articulation disorder: "Incorrect production of speech sounds due to faulty placement, timing, direction, pressure, speed, or integration of the movements of the lips, tongue, velum, or pharynx" (Nicolosi, Harryman, \& Kresheck, 1983, p. 15). 
Development apraxia of speech: a neurological disorder characterized by motor programming and execution difficulties for the voluntary production of speech (Abbs \& Rosenbek, 1986; Jaffe, 1984; Morley \& Fox, 1969; Nelson, 1989; Yoss \& Darley, 1974a).

Phonologic assessment/analysis: describes speech sound errors by phonological process use.

Phonologic disorder/impairment: occurs: "l) at the articulatory or phonetic level which involves mastery of the motor ability, and 2) at the phonologic level which involves the organizational aspects of the sound system" (Weiss, Gordon, \& Lillywhite, 1987, p. 63).

Phonological process: a child's simplification of an adult sound production; some processes are normal occurring, others occur only in deviant speech; may occur for an entire sound class (Hodson \& Paden, 1983).

The following acronyms will be utilized throughout the study. APP-R: Assessment of Phonologic Processes - Revised (Hodson, 1986) articulation test used for the assessment of phonologic errors. CAPP: Computer Assessment of Phonological Process (Hodson, 1985) computer program which analyzes results from the APP-R.

DAS: Developmental Apraxia of Speech.

FAD: Functional Articulation Disorder. MAD: Multiple Articulation Disorder.

For other definitions of phonological process terms refer to Appendix A. 


\section{REVIEW OF THE LITERATURE}

According to the American Speech-Language-Hearing Association, 5 percent of children between the ages of 5 and 21 have speech disorders (McReynolds, 1986). The most common speech disorder is articulation disorder which makes up approximately 60 percent of all communication disorders (Haynes, 1985). Often individuals have multiple articulation errors. These multiple errors are known as multiple articulation disorder (MAD). This disorder can appear anytime during the development of phonemes and continue into later childhood. One type of MAD is DAS, which is present at birth although it may not be evident until later in development. DAS is believed to be an impaired motor disorder. Another type of MAD which seems to occur quite frequently is FAD, which is an articulation disorder with no apparent organic etiology. FAD and DAS can be present in varying degrees of severity, with the degree of severity influencing the course of remediation (Mc Reynolds, 1986).

\section{MULTIPLE ARTICULATION DISORDERS}

Articulation disorders have been described by a wide variety of characteristics. Weiss, Gordon, and Lillywhite (1987) present the following general characteristics: (a) normal order of development 
for speech sounds, (b) errors in speech sound production, (c) orderly misarticulations relative to phoneme structure and to relationships to other phonemes, (d) inconsistency in speech sound production (i.e., placement in word), (e) use of easier forms of articulation and phonologic patterns, (f) substitution of one sound for another, and ( $g$ ) in some cases, impaired oral sensory and motor abilities. These various error productions may not all be present, but, singly or in combination, designate an articulation disorder. DAS and FAD are two disorders whose characteristics have not been clearly defined. Often, speech sound disorders which are not categorized by any other label are lumped together into the category of FAD making it into a wastebasket term.

Identification of characteristics of a disorder provide information about the symptoms of the disorder, but knowledge of etiology is also necessary for more accurate diagnosis and treatment (Bernthal \& Bankson, 1988). According to McReynolds (1986), the etiology for FAD has not been identified. The variables of intelligence, motor skills, auditory discrimination, auditory memory, socio-economic status, personality, sex, academic performance, and dentition have been explored without a significant causal factor being identified. It has been assumed by the profession that FAD has multiple causes.

\section{DEVELOPMENTAL APRAXIA OF SPEECH}

An articulation disorder which also seemingly has an unknown etiology and the symptom of multiple errors is DAS. A century ago, Dr. W.B. Hadden, M.D., described a client of his with symptoms which 
some now believe to be the disorder of apraxia (Haynes, 1985). Dr. Hadden described a subject with unintelligible speech characterized by inconsistent errors. The list of characteristics which have been associated with DAS since that time is lengthy. For the purposes of this paper, only those characteristics which relate to speech production in children will be presented. Table I lists characteristics which have been identified from research as being indicative of DAS. There are many characteristics associated with DAS. A select group of these characteristics are given credit for distinguishing between DAS and FAD.

\section{DIFFERENTIATING FAD FROM DAS}

Several researchers have identified characteristics which they attribute to DAS: (a) voicing feature errors (Yoss \& Darley, 1974a); (b) impaired volitional oral movements (Yoss \& Darley, 1974a); (c) sound omissions (Smart, LaLance, Gray, \& Hibbett, 1976); (d) clusters of symptoms (Blakeley, 1983; Jaffe, 1984; Yoss \& Darley, 1974a); (e) attention, discrimination, and memory deficits (Prichard, Tekieli, \& Kozup, 1979); and (f) length of remediation (Morely, 1972; Jaffe, 1984). These symptoms have been reported in the literature as observable differences between DAS and FAD.

Yoss and Darley (1974a) found the use of volitional oral movements to be significantly different between two groups of subjects, one with FAD and the other with DAS. The latter subjects with DAS were found to have restricted use of both isolated and sequential oral movements. This deficiency is indicative of the commonly 


\section{TABLE I}

\section{CHARACTERISTICS OF DAS REPORTED IN THE LITERATURE}

Non-Speech Characteristics

Oral perception insufficient for normal functioning (Prichard, Tekieli, \& Kozup, 1979).

Oral nonverbal apraxia often also present (Chappe11, 1973; Rosenbek \& Wertz, 1972; Yoss \& Darley, 1974a).

\section{Speech Characteristics}

Use of fewer phonemes (Edwards, 1973; Morley, 1972).

Remarkably deficient imitative skil1s (Chappe11, 1973; Rosenbek, Hansen, Baughman, \& Lemme, 1974).

Errors appearing in an exceedingly unstable manner (Nicolosi,

Harryman, \& Kresheck, 1983; Rosenbek \& Wertz, 1972).

Difficulty with phonetic synthesis (McClumpha \& Logue, 1972).

Fewer misarticulations at the spontaneous level than at the imitative leve 1 (McClumpha \& Logue, 1972; Rosenbek, 1982).

Speech development delayed and accompanied by deviations (Aram \& Glasson, 1979; Rosenbek \& Wertz, 1972).

Phonemic errors being primarily omissions, followed by distortions, additions, repetitions, and prolongations (Rosenbek \& Wertz, 1972 ).

Vowel and consonant misarticulation (Rosenbek \& Wertz, 1972).

Sound $s$ in isolation repeated satisfactorily, with connected speech of greater unintelligibility than would be predicted from articulation tests using single words (Rosenbek \& Wertz, 1972). Degree of articulatory movements determining variability of errors (Crary, 1982).

Errors most commonly occurring on fricatives, affricates, and consonant clusters (Rosenbek \& Wertz, 1972).

Sound prolongations, repetitions, or silent posturing resulting from groping trial and error posturing (Rosenbek \& Wertz, 1972).

Sequencing errors and slow rate on diadochokinetic task (Aram \& Glasson, 1979 ; Crary, 1982).

Increased number of voicing errors over FAD (Yoss \& Darley, 1974a). Repeated speech: errors of two and three features, sound prolongations and sound and/or syllable repetitions, distortions and additions (Yoss \& Darley, 1974a).

Spontaneous speech: feature errors of one place, additions, and omissions (Yoss \& Darley, 1974a).

Problems sequencing sounds and longer utterances, difficulty related to complexity and length, most difficulty with polysyllabic words (Chappe11, 1973, Edwards, 1973; Morley, 1972; Rosenbek \& Wertz, 1972; Yoss \& Darley, 1974a).

Oral-nasal resonance misuse (Yoss \& Darley, 1974a).

Spatial and temporal coordination difficulty (Crary, 1981). Increased omissions over FAD (Smart, LaLance, Gray, \& Hibbett, 1976). 
proposed nature of DAS, i.e., the involuntary movements of the articulators operate smoothly, but the voluntary movements of the same articulators operate over a range of degrees of deficit (Nelson, 1989). Yoss and Darley (1974a) reported the voicing feature as another potentially distinguishing characteristic. Subjects with DAS were found to have two times as many voicing errors as subjects with FAD. In addition to impaired volitional oral movements and voicing features, lower diodochokinetic rates, difficulty with polysyllabic words, modified prosody, additions, and a group of error features (i.e., two- and three-feature errors, place errors) were suggested as possible indicators of DAS.

Williams, Ingham, and Rosenthall (1981) reported an attempt to replicate Yoss and Darley's (1974a) study, but their type of subjects, as well as their results, differed. The subjects were divided into two groups. One group presented with MAD while the other was a control group of children with normal production. No children previously identified with DAS were used in the Williams et al. (1981) study. They reported that although the scope of symptoms was similar to those found by Yoss and Darley (1974a), no significant differences were found. They explained that the difference found in Yoss and Darley's (1974) study was due to the choice of subjects. They felt that predetermining DAS subjects, as Yoss and Darley (1974a) had done, interfered with the research design and the significance of the data.

Several authors have reported a cluster of symptoms as indicative of DAS (Blakeley, 1983; Jaffe, 1984; Rosenbek \& Wertz, 1972; Yoss \& Darley, 1974a). Yoss and Darley (1974a) identified groups of 
symptoms in clusters in both repeated speech and spontaneous speech as significant. The errors in repeated speech were two- and threefeature errors, sound prolongations and sound and/or syllable repetitions, distortions, and additions. Rosenbek and Wertz (1972) identified a cluster of symptoms composed of vowel errors, increased errors on longer responses, and groping postures. Jaffe (1984) pointed out that the variety of clusters reported only add an element of question to the problem of differential diagnosis. This researcher hypothesizes that symptom clusters may define subcomponents of disorders within MAD.

One phenomenon which is consistently reported in the literature as characteristic of DAS is resistance to modification (Chappe11, 1973 ; Hal1, 1989; Rosenbek, Hansen, Baughman, \& Lemme, 1974; Yoss \& Darley, 1974b). Hall (1989) reported a retrospective study of children who had difficult to remediate, mild $/ r /$ misarticulations. Over time, other symptoms associated with DAS became apparent in these subjects, i.e., groping and posturing, as well as prosodic irregularities, but their resistance to treatment was apparent early in the remediation.

With the identification of characteristics for DAS, researchers have speculated about the etiology. Several hypotheses have emerged to explain the nature of DAS. Jaffe (1984) maintains that there could be a developmental element; for example, the cluster of symptoms may change as the child with DAS matures. This factor could present different clusters of symptoms for various developmental stages of DAS. The varying degrees of severity could have an effect on 
the characteristics which are exhibited (Jaffe, 1984). Some authors have suggested that DAS is merely a component of other disorders and not truly an entity in itself. Guyette and Diedrich (1981) maintained that DAS is without empirical evidence to support its classification as a clinical population. They also stated that the diagnosis today is based on clinical observation, not empirical evidence. Jaffe (1984) suggested that differentiating DAS from FAD may not be possible, considering current information. Until more research is completed, many questions will remain unanswered.

\section{APPROACHES TO REMEDIATION OF FAD AND DAS}

Currently, there are three different approaches to remediation of articulation errors, i.e., discrimination, production, and linguistic (McReynolds, 1986). Each of these approaches is based on a different hypothesis concerning the etiology of the disorder.

A sound discrimination approach was developed by Van Riper and Irwin (1958), which attributes the articulation errors to difficulty in discriminating one sound from another. Another model developed by Winitz (1984) attributes the difficulty to phonological structure and focuses on the child's perception of a sound. Winitz stated that there is a strong relationship between discrimination and production. He found articulation errors to be related to one or more of the following components: (a) lack in discrimination ability; (b) discrimination is intact, but due to a personal phonological rule, changes in the discrimination occur; (c) limits of the articulators interfere with production,; and (d) learning strategies interfere 
with attending and consequently, production. The approach to treatment focuses on auditory discrimination, as well as sound production. While Van Riper and Irwin (1958) and Winitz (1984) emphasized the perceptual aspects, others have focused on the production of the target sounds. A production approach to remediation was developed by McDonald (1964), who attributed the child's speech production deficits to deviant sensory motor development. He used the syllable as the smallest speech component. McDonald (1964) stated that movements of the articulators are not sequenced, but extend over into each other and occur nearly at the same time. The coarticulated movements cause the sounds to have considerable effect on each other and require fine motor coordination skills. According to McDonald (1964), children's development may stop at a lower level of sensory motor development and therefore their ability to produce sounds is not age-appropriate.

A third approach to remediation is the linguistic approach. It has been applied to communication disorders with less emphasis in the area of phonology (McReynolds, 1986). Two linguistic approaches which frequently are described in the literature are distinctive features and phonological processes. The distinctive feature approach considers each phoneme to be a composite of features and therefore phonemes are categorized by features they have in common. Sounds in isolation, nonsense syllables, and words are frequently contrasted to demonstrate their distinctive features (Weiss et al., 1987). A phonological processes approach is a linguistic approach based on the learning of phonological rules and the assumption that a 
phonological process affects patterns of errors at the word leve 1 (Weiss et al., 1987). Errors reflect the use of incorrect phonological patterns in words. These incorrect patterns are described as processes, or simplified versions of the adult form (Hodson \& Paden, 1983; Ingram, 1982; Stoe1-Gammon \& Dunn, 1985; Weiss et a1., 1987).

Researchers have demonstrated use of phonological processes by normally developing children (Hodson \& Paden, 1981; Preisser, Hodson, \& Paden, 1988) as we 11 as by those with FAD (Dunn \& Davis, 1983; Yoss \& Darley, 1974a). Research is limited in the area of DAS use of phonological processes.

Preisser et al. (1988) investigated use of phonological processes by phonologically normal children between the ages of 18 and 29 months. The results identified cluster reduction and liquid simplification as the processes which were used by significantly more children than any of the other processes. Stridency deletion, velar and nasal/glide deviations, postvocalic obstruents, syllable reduction, and prevocalic abstruent followed in means of percentage of occurrence, respectively. The mean percentage of occurrence for all processes used by the younger subjects was well above that of the older subjects. Preisser et al. (1988) demonstrated the use of phonological processes by normally developing children during the period of development of single- and multi-word utterances.

\section{PHONETIC VS. PHONOLOGIC ERRORS}

There appear to be two levels of involvement in articulation disorders, phonetic and phonologic. The phonetic errors are 
considered to involve a motor control area of the brain, whereas the phonologic errors are considered to involve a higher level of the brain where rules for grouping phonemes are programmed (Compton, 1970). The phonetic level deals with individual phoneme production, while the phonological deals with patterns of errors in groups of phonemes (Compton, 1970). Luce and Pisoni (1987) stated that phonological and morphological rules are applied to the "acoustic-phonetic waveform" (p. 18). Children with phonological errors are able to discriminate accurately and produce the correct sounds, but they use simplified forms of adult words which appear to follow what have been referred to as phonological principles. These principles direct the formation of phonemes into phonetic forms, i.e., words (Compton, 1970).

Knowledge of phonological rules when applied to treatment produce positive results. According to Compton (1970) and Hodson and Paden (1981), clinicians have reported that remediation of one phoneme often produces improvement in other phonemes. This generalization phenomenon is indicative of the phonological principles underlying the production of the group of phonemes. In his study of remediation for nasalization of vowe 1 s preceding nasal consonants, Compton (1970) trained only final/m/ and yet the correct production generalized to the other nasal consonants, $/ \mathrm{n} /$ and $/ \mathfrak{y} /$. This generalization factor is a major component of the phonological process approach to treatment (Hodson \& Paden, 1983). 
USE OF PHONOLOGICAL PROCESSES IN MULTIPLE ARTICULATION DISORDERS

Hodson and Paden (1981) and Dunn and Davis (1983) identified processes used by children with MAD. Hodson and Paden (1981) compared two groups of 60 four- to five-year-old subjects with MAD. The two groups were categorized as intelligible and unintelligible. It is not known if any of the subjects demonstrated DAS. The inte11igible group consistently used only the process of final consonant devoicing. Those with unintelligible speech used cluster reduction, stridency deletion, stopping, liquid deviation, and assimilation. Hodson and Paden (1981) determined these processes to be the key processes shared by children with unintelligible speech. The following processes were used less often by the unintelligible group, and not used by the intelligible group: velar deviations, final consonant deletion, weak syllable deletion in three- and four-syllable words, prevocalic voicing, glottal replacement, and backing. Hodson and Paden (1981) stated that children with MAD characterized by unintelligible speech use different strategies when using phoneme classes and applying processes than the intelligible children. This research demonstrates that the processes used by children with MAD characterized by unintelligible speech are different from those used by children with MAD characterized by intelligible speech.

Further identification of process use for children with MAD was reported by Dunn and Davis (1983) who studied the individual use and frequency of occurrence of phonological processes. They did not report if any of the subjects demonstrated DAS. Nine subejcts, ages 
3.8 to 5.10 years, were assessed for use of Shriberg's natural processes and reduplication. Shriberg's natural processes include final consonant deletion, velar fronting, stopping, palatal fronting, liquid simplification, cluster reduction, assimilation, and unstressed-syllable deletion. Additionally, the unusual processes of deletion of initial consonant, deletion of medial consonant, addition of a unit, metathesis, backing, and substitutions not accounted for by the natural processes, e.g., $d / 1$ and $f / t$ were assessed. The seven processes most frequently used were cluster reduction, liquid simpliEication, depalatalization, velar fronting, deletion of final consonant, stopping, and unstressed syllable deletion. Dunn and Davis (1983) stated that these seven processes accounted for two-thirds of the errors. They also reported that the frequency of use of these processes by children with MAD varied considerably. The results of this study showed agreement with Hodson and Paden's (1981) study in that subjects with MAD demonstrated use of a small group of processes. Both studies identified cluster reduction, stopping, liquid deviations, velar deviations, final consonant deletion, and weak syllable deletion as the most commonly occurring processes for MAD.

\section{Assessment Instruments}

Several authors have developed assessment instruments for phonological processes (Hodson, 1986; Ingram, 1981; Kahn \& Lewis, 1986; Shriberg \& Kwiatkowski, 1980; Weiner, 1979). Weiner developed the Phonological Process Analysis (PPA) (1979), in which both single words and phrases are used to elicit specific phonemes. The 
categories of syllable structure processes, harmony processes, and feature contrast processes are analyzed for a total of 18 processes (Weiss et a1., 1987).

Another phonological instrument, the Natural Process Analysis (NPA) was devised by Shriberg and Kwiatkowski (1980). The eight processes assessed are final consonant deletion, velar fronting, stopping, palatal fronting, liquid simplification, regressive and progressive assimilation, cluster reduction, and unstressed syllable deletion. Shriberg and Kwiatkowski labeled them natural processes because (a) the processes occur in the speech of preschool and elementary school children having delayed speech, (b) the processes simplify an adult structure, and (c) there is reliability in scoring (Creaghead, Newman, \& Secord, 1989; Weiss et a1., 1987). The NPA elicits a spontaneous language sample which is then analyzed for phonetic and phonologic errors.

Ingram (1981) developed the Procedures for the Phonological Analysis of Children's Language ( phonological processes are assessed in addition to phonetics, homonymy, and substitutions (Weiss et $81 ., 1987$ ). Spontaneous language sample, elicited words, and/or diary form can be used to accumulate the sample for the PPACL.

The Kahn-Lewis Phonological Analysis (KLPA) developed by Kahn and Lewis (1986) assesses 15 phonological processes by elicitation of 44 words. Their instrument was designed for children with some degree of unintelligible speech. Data for the phonological analysis is completed using the sounds-in-words subtest of the Goldman-Fristoe 
Test of Articulation (Goldman-Fristoe, 1986). The phonetic transcription of the child's word productions are analyzed using the KLPA (1986).

Hodson (1986) developed the Assessment of Phonological

Processes - Revised (APP-R) (1986). This instrument was chosen for this research because of its broad scope and the ease of scoring, with its companion computer software program. It assesses phonological omissions, class deficiencies, phonemic substitutions, and miscellaneous error patterns such as assimilations, voicing errors, and articulatory shifts, for a total of 40 processes. The four omission and six class deficiency categories comprise the basic phonological processes as labeled by Hodson. Single-word utterances, elicited by 50 objects, are used to collect the speech sample. Hodson justifies the use of single words to collect the speech sample in view of the unintelligibility of subjects with severe MAD. Computer software for the APP-R (1986) is the CAPP (Hodson, 1985), which analyzes the frequency of occurrence and percentages of the ten basic processes, assigns a severity level, and specifies treatment targets. 
CHAPTER III

METHODS

SUB JECTS

The 18 subjects, ages 5.9 to 12.1 years, attending public elementary schools in the greater Portland, Oregon, metropolitan area were diagnosed by their public school speech-langauge pathologists (SLPs) as having moderate to severe MAD of unknown etiology. Prior to this study, the subjects participated in another study conducted by Woodward (1990) in which they were required to pass a bilateral pure tone audiometric screening at $20 \mathrm{~dB}$ for the frequencies of 500 , 1000,2000 , and $4000 \mathrm{~Hz}$. In addition, the subjects responded to a test battery including (a) the Peabody Picture Vocabulary Test -

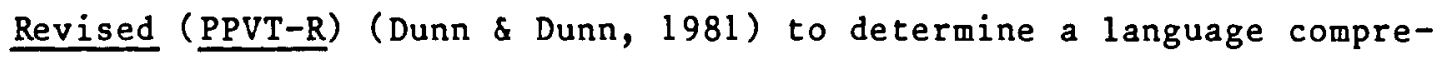
hension age; (b) three subtests of either the Test of Language Deve lopment - Primary (TOLD-P) (Newcommer \& Hammil1, 1982) or the Test of Language Development - Intermediate (TOLD-I) (Newcommer \& Hammi11, 1982) to determine an expressive language age; (c) Arizona Articulation Proficiency Scale - Revised (AAPS-R) (Fudala, 1982) to establish an articulation disorder severity rating, and (d) the Screening Test of Deve lopmental Apraxia of Speech (STDAS) (Blakeley, 1980) to screen for the presence of DAS. Of the 18 subjects, 10 were assessed by Woodward (1990) as demonstrating DAS as 
determined by results from the STDAS (Blakeley, 1980). The other eight subjects were determined to have FAD by results from the STDAS (Blakeley, 1980). Of the 18 subjects, 14 were determined to be severely disordered and 4 were determined to be moderately disordered by the AAPS-R. For the STDAS, a total raw score of 27 or greater, or a weighted score of -60 or less was used to determine the presence of DAS. In addition, the subjects did not display mental retardation, hearing impairment, visual impairment, social-emotional impairment, multiple handicaps, or other impairments which would interfere with speech sound production. This was determined by public school records and investigator observation. The independent variables which were not controlled were sex, socio-economic status, and geographic distribution. Release forms, signed by the parent, were obtained for each subject prior to participation in the study (Appendix B).

\section{INSTRUMENTATION}

The instruments used in this research are described below. Stereo cassette recorder. An AIWA stereo cassette recorder with an external microphone was used to record each subject's test productions on Maxe11 XLII-S 100 cassettes.

APP-R (Hodson, 1986). The APP-R is a test of the use of phonological processes. The instrument assesses ten basic phonological processes, i.e., phonological omissions of syllable reduction, consonant sequence reduction, consonant singleton omission (prevocalic and postvocalic), as we 11 as the class deficiencies of strident, velar obstruent, liquids $/ r /$ and $/ 1 /$, nasal, and glide. In addition, 
the phonemic substitutions, assimilations, voicing alterations and place shifts are assessed. Refer to Appendices $C$ and $D$.

CAPP (Hodson, 1985). The CAPP is a software program used to analyze the ten phonological processes assessed by the APP-R. it provides percentage of occurrence for each of the ten processes, the average of occurrence for the ten processes, deviancy score, and severity rating. Refer to Appendix E.

\section{PROCEDURES}

\section{Experimental Procedures}

After meeting subject selection criteria, this researcher administered the APP-R (Hodson, 1986) according to manual instructions to all subjects. It was administered individually in a quiet room in the subject's school with the subject seated across a small table from the examiner with the subject's face in full view of the examiner. Subjects were asked to give their names and birthdates. Fifty test objects were presented individually to the subjects to be verbally labeled. The examiner simultaneously recorded their phonetic productions by hand on the test form, as well as by tape recorder on audio cassette tape.

\section{$\underline{\text { Reliability }}$}

Intra-rater reliability was established by the researcher retranscribing 10 percent of the data for 18 subjects 1 to 3 weeks after testing. A sound-by-sound comparison established intra-rater reliability at 95 percent. Inter-rater reliability was established 
by a graduate student in the Master's program in Speech-Language Pathology at PSU, transcribing 4 of the 18 transcripts simultaneously with this researcher. Inter-rater reliability was established sound by sound by comparing phonetic transcriptions with a mean percentage of agreement of 94 percent.

\section{DATA SCORING AND ANALYSIS}

Each subject's production of onissions and class deficiencies was analyzed by the CAPP (Hodson, 1985) and the percentages of process occurrence for each of the ten basic processes were determined by this computer program. Analysis was completed by hand for select processes in the categories of phonemic substitutions, assimilations, and voicing alterations by determining the number of times each process was used. The total average percentage of occurrence of the ten basic phonological processes and the deviancy score were calculated for each subject, as we 11 as the means and standard deviations for each group. The SYSTAT (Wilkinson, 1988) computer software statistical program was used to perform t-tests and ANCOVA. Two-tailed $\underline{t-}$ tests for independent measures were used to determine if a statistically significant difference existed (a) in the mean percentage of use of the ten basic processes and (b) the mean deviancy score between the two groups of subjects. If the absolute value of the $\underline{t}-$ test was beyond the .05 level of confidence, the difference of means was interpreted as significant. Post hoc $t$-test analysis on individual processes was completed on the ten basic processes and on other selected processes as deemed appropriate by visual inspection. 
CHAPTER IV

RESULTS AND DISCUSSION

RESULTS

The purpose of this study was to compare the use of phonological processes by elementary school-age children who have moderate to severe FAD (MAD without DAS) with elementary school-age children who have DAS. The APP-R/CAPP was administered to 18 subjects, ranging in age from 5.9 to 12.1 years. Within three weeks of the present study, an articulation disorder severity rating was established in addition to the grouping of subjects into FAD and DAS categories. The articulation disorder severity rating was established by scores on the AAPS-R, and scores on the STDAS were used for categorizing subjects into the groups of FAD and DAS. The results reported below must be interpreted with caution considering three limiting factors: (a) the small number of subjects, (b) grouping by the STDAS, and (c) small age range.

The first question to be addressed follows. Is there a significant difference in the Average of Phonological Process scores for school-age children who demonstrate FAD and DAS? A phonetic transcript for each subject, from the APP-R/CAPP, was analyzed by the 
computer. The Average of Phonological Process scores for the APP-R/CAPP, listed by age, for both FAD and DAS groups are shown in Table II.

\section{TABLE II}

AVERAGE OF PHONOLOGICAL PROCESS USE BY FAD AND DAS SUBJECTS

Functional Articulation Disorder (FAD)

\begin{tabular}{ll}
\hline & $\begin{array}{l}\text { Average } \\
\text { of Phono- }\end{array}$ \\
Severity & $\begin{array}{l}\text { logical } \\
\text { Leve1 on }\end{array}$ \\
Process \\
Subject Age AAPS-R
\end{tabular}

F1

F2

F3

F4

F5

F6

F7

F8
5.9

6.2

6.9

6.11

7.1

7.4

7.6

9.1
AAPS $-R$

$M$
$M$
$M$
$M$
$S$
$S$
$S$
$S$

$$
24
$$

23

7

12

9

14

14

9

Developmental Apraxia of Speech (DAS)

\begin{tabular}{ll} 
Average & $\begin{array}{l}\text { Af Phono- } \\
\text { of }\end{array}$ \\
Subject Agerity logical \\
Level on & $\begin{array}{l}\text { Process } \\
\text { AAPS-R Usage }\end{array}$ \\
\hline
\end{tabular}

D1

$$
5.10
$$$$
6.0
$$

27

D2

6.1

45

D3

D4

6.2

35

D5

6.3

20

35

D6

6.6

37

D7

6.11

46

D8

6.11

26

D9

7.6

D10 12.1
18

17

$M=$ Moderate

$S$ = Severe

The DAS group used more phonological processes than the FAD group as demonstrated by their Average of Phonological Process scores with a mean score of $30.6(S D=10.617)$ for the DAS group and a mean score of $14(S D=6.370)$ for the FAD group. This difference was shown to be statistically significant by the use of a two-tailed ttest for independent means using a confidence level of .05. The pooled variance $\underline{t}$ value of 3.885 indicated a statistically significant difference between the two groups of the Average of Phonological Processes (Table III). 


\section{TABLE III}

t-TEST RESULTS ON AVERAGE OF PHONOLOGICAL PROCESS USAGE SCORES FOR FAD AND DAS SUBJECTS

$\underline{\text { Score }}$ Group Mean

$\underline{S D}$

d.

t-value

P

Average of

FAD $\quad 14.00$

6.37

16

3.885

$\star 0.01$

Phonological

Processes

DAS

30.06

10.62

16

3.885

$\star 0.01$

* = Significant $(\mathrm{p}<.05)$.

An analysis of covariance (ANCOVA) was applied to allow for the diverse grouping of moderate and severe disorders. A statistically significant difference was determined by the ANCOVA using scores adjusted for the AAPS-R severity rating. The DAS group, with an adjusted mean of 31.71 , was significantly higher in phonological process use than the FAD group, with an adjusted mean of $12.61([F(1,15)$ $=12.524, P=\langle 0.01\}$ (Table IV). Therefore, the subjects with DAS used more phonological processes than the subjects with FAD, even when controlling for severity level.

\section{TABLE IV}

ANCOVA RESULTS ON AVERAGE OF PHONOLOGICAL PROCESS USAGE SCORES FOR FAD AND DAS SUBJECTS

Group

FAD

DAS

* = Significant $(p<.05)$
F-Ratio

P

$$
(1,15)=12.52 \quad * 0.01
$$

In addition to the Average of Phonological Process score, the Phonological Deviancy Score was computed by the APP-R/CAPP analysis. 
The Phonological Deviancy Score is an overall score adjusted for age which is used to determine the Severity Interval. The DAS group with a mean score of $46.60(S D=9.62)$ had a higher Phonological Deviancy Score than the FAD group with a mean score of $9.0($ SD $=16.70)$. A two-tailed t-test for independent means using a confidence leve 1 of .05 demonstrated a significant difference between the two groups. The pooled variance $t$-test value of 3.89 indicted a statistically significant difference between the two groups for Phonological Deviancy Score (Table V).

\section{TABLE $V$}

t-TEST RESULTS ON PHONOLOGICAL DEVIANCY SCORES FOR FAD AND DAS SUBJECTS

Score

Phonological

Deviancy

Score

* = Significant $(p<.05)$.

Group
FAD
DAS
$(p<.05)$.

$\underline{S D}$

d. f.

t-Value

P

$9.00 \quad 16.70$

16

3.89

$* 0.01$

46.60

9.62

16

3.89

$* 0.01$

An ANCOVA using Phonological Deviancy Scores adjusted by the AAPS-R severity rating demonstrated a significant difference between the two groups when scores were adjusted for the moderate and severe grouping of subjects (Table VI). The DAS group with an adjusted mean score of 50.60 was significantly more deviant than the FAD group with an adjusted mean score of $4.0 f F(1.15)=43.562, p=0.01\}$.

The second question posed is as follows. Do children with DAS use different phonological processes than children with FAD? The means and standard deviations for the omission phonological 
TABLE VI

ANCOVA FOR ADJUSTED GROUP MEANS ON PHONOLOGICAL DEVIANCY SCORES FOR FAD AND DAS GROUPS

$\begin{array}{lccc}\text { Group } & \frac{\text { Adjusted Mean }}{\text { FAD }} & \text { F-ratio } & \text { p } \\ \text { DAS } & 4.00 & (1 / 15)=43.562 & \star 0.01\end{array}$

$\star=$ Significant $(\mathrm{p} \& .05)$

processes considered for each group as well as the $\underline{t}$-test scores appear in Table VII. For the APP-R/CAPP category of omissions, the children with DAS demonstrated a statistically significant difference in the use of consonant sequence as determined by use of a two-tailed $\underline{t}$-test for independent means (Table VII). For consonant sequence, a mean of $48.90(S D=29.67)$ for the DAS group was significantly different from the mean of $4.63(S D=4.78)$ for the FAD group $(d f=4.2$, $P=0.01)$. Syllable reduction, prevocalic singleton, and postvocalic singleton were not found to differentiate between the two groups. For syllable reduction, a mean of 0.01 ( SD $=0.01$ ) for the DAS group and a mean of $2.63(S D=5.68)$ for the FAD group provided insufficient data for a statistical test. For prevocalic singleton, a mean of $1.70(S D=2.11)$ for the DAS group and a mean of 0.01 (SD $=$ $0.01)$ for the FAD group also provided insufficient data for a statistical test. For postrocalic singleton, a mean of $6.70(\mathrm{SD}=$ 12.70) for the DAS group was not significantly different from the mean of $0.38(\mathrm{SD}=1.06)$ for the FAD group as determined by a twotailed $\underline{t}$-test for independent means $(\mathrm{df}=1.40, \mathrm{p}<0.18)$. 
TABLE VII

MEAN PERCENTAGE OF OCCURRENCE AND $t$-TEST RESULTS FOR OMISSIONS FOR FAD AND DAS GROUPS

Pattern

Syllable

Reduction

Prevocalic

Singleton

Postrocalic

Singleton

Consonant

Sequence

\section{Group}

FAD

DAS

Mean

2.63

0.01

FAD $\quad 0.01$

DAS 1.70

FAD $\quad 0.38$

DAS 6.70

FAD $\quad 4.63$

DAS $\quad 48.90$

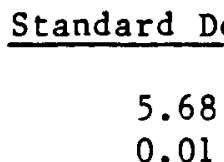

0.01

2.11

1.06

12.70

4.78

29.67 d.f. $t \quad$ R

Insufficient Data for $t$-Test

Insufficient Data for $t$-Test

$16 \quad 1.4 \quad 0.18$

$16 \quad 4.2 * 0.01$

* = Significant $(\mathrm{p}<.05)$.

For the APP-R/CAPP category of class deficiencies, the DAS group was more deficient in the areas of strident, velar, liquid (1), and glides (Table VIII). In strident deficiency, the DAS group mean was 41.10 ( $S D=25.55)$ while the FAD group mean was $9.50(S D=8.90)(t=$ 3.3, $\mathrm{p}(0.01)$. In velar deficiency, the DAS group mean was 37.30 $(S D=25.36)$ while the FAD group mean was $6.38(S D=6.02)(t=3.4$, p $(0.01)$. In the liquid (1) deficiency, the DAS group mean was $57.50(S D=24.41)$, while the FAD group mean was $23.88(S D=34.44)$ $(t=2.4, p<0.03)$. In glide deficiency, the DAS group mean was $27.00(S D=20.58)$, while the FAD group mean was $2.50(S D=4.63)(t$ $=3.3, \mathrm{p}(0.01)$. There was no significant difference shown between mean scores for the two groups in nasal and liquid $(r)(p>.05)$. The DAS group mean for nasal was $3.70(S D=4.47)$ while the FAD group mean was $2.0(S D=4.04)(t=0.8, p<0.42)$. The DAS group mean 
for liquid $(r)$ was $82.20(S D=18.86)$ while the FAD group mean was $86.75(S D=13.64)(t=-0.6, p(0.58)$.

\section{TABLE VIII}

MEAN PERCENTAGE OF OCCURRENCE AND $t$-TEST RESULTS FOR CLASS DEFICIENCIES FOR FAD ANND DAS GROUPS

$\underline{\text { Pattern }}$ Group Mean Standard Deviation d.f. $\underline{t} \quad \mathrm{R}$

Stridents

FAD

DAS

9.50

41.10

FAD

DAS

6.38

37.30

Liquid

$\begin{array}{lll}\text { (1) FAD } & 23.88 \\ & \text { DAS } & 57.50\end{array}$

Liquid ( $r$ )

FAD

86.75

82.20

FAD

DAS

2.00

3.70

2.50

27.00
8.90

25.50

6.02
25.36

34.44

24.41

13.64

18.86

4.04

4.47

4.63

20.58
$16 \quad 3.3 \quad * 0.01$

$16 \quad 3.4 \quad * 0.01$

$16 \quad 2.4 \quad * 0.03$

$\begin{array}{lll}16 & -0.6 & 0.58\end{array}$

$\begin{array}{lll}16 & 0.8 & 0.47\end{array}$

$16 \quad 3.3 * 0.01$

$*=$ Significant $(p<.05)$

The phonemic substitution categories of deaffrication and metathesis were analyzed by hand. For deaffrication substitution, no significant difference was shown between the scores for the two groups at $p>.05$ (Table IX). The DAS group mean was 0.90 ( $\mathrm{SD}=$ 1.20) while the FAD group mean was $0.38(S D=0.59)(t=1.2, p<$ 0.27). For metathetic substitutions, no significant difference was shown between the scores for the two groups at $p>.05$. The DAS group mean was $0.70(S D=1.06)$ while the FAD group mean was 0.75 $(S D=1.04)(t=-0.10, p<0.92)$. 
For the category of assimilation, the DAS group with a mean of $3.30(S D=1.89)$ and the FAD group with a mean of $0.88(S D=1.13)$ demonstrated a significant difference in the use of assimilation as determined by a one-tailed $t$-test for independent means using a confidence level of .05 . The pooled variance t-test value of 3.20 indicated a statistically significant difference between the two groups (Table IX).

Finally, for the category of voicing alterations, the DAS group with a mean of $3.10(S D=3.04)$ and the FAD group with a mean of 1.63 $(S D=1.69)$ did not demonstrate a significant difference in the use of voicing alterations as determined by the use of a two-tailed

\section{TABLE IX}

MEAN PERCENTAGE OF OCCURRENCE AND $t$-TEST RESULTS FOR PHONEMIC SUBSTITUTIONS, ASSIMILATIONS, AND VOICING ALTERATIONS FOR FAD AND DAS GROUPS

Pattern Group Mean Standard Deviation d.f. $\underline{t} \quad$ R Phonemic Substitutions

$\begin{array}{lllllll}\text { Metathesis } & \text { FAD } & 0.75 & 1.04 & 16 & -0.1 & 0.92 \\ & \text { DAS } & 0.70 & 1.06 & & & \\ & & & & & & \\ \text { Deaffri- } & \text { FAD } & 0.38 & 0.52 & 16 & 1.2 & 0.27 \\ \text { cation } & \text { DAS } & 0.90 & 1.20 & 0.20\end{array}$

Assimilations

$\begin{array}{llllll}\text { FAD } & 0.88 & 1.13 & & & \\ \text { DAS } & 3.30 & 1.89 & 16 & 3.1 & * 0.01\end{array}$

Voicing Alterations

$\begin{array}{llllll}\text { FAD } & 1.63 & 1.69 & & & \\ \text { DAS } & 3.10 & 3.04 & 16 & 1.2 & 0.24\end{array}$


$\underline{t-t e s t}$ for independent means using a confidence level of .05 . The pooled variance $\underline{t}$-test value of 1.23 indicated so statistically significant difference between the two groups (Table IX).

An analysis of covariance (ANCOVA) was completed for each of the statistically significant pattern deviations to allow for the grouping of moderate and severe subjects. The percentage of occurrence of process scores were adjusted according to each subject's severity score on the AAPS-R. All of these same processes were found to be significant using the $t$-test were also found to be significant using the ANCOVA, therefore the inclusion of moderate subjects within the study appears not to have affected the results. The adjusted means are reported in Table $X$.

\section{TABLE $X$}

ANCOVA FOR GROUP MEANS OF PATTERN DEVIATIONS FOR FAD AND DAS GROUPS

\begin{tabular}{|c|c|c|c|c|c|}
\hline Pattern & Group & Mean & d. f. & $\underline{t}$ & $\mathrm{p}$ \\
\hline $\begin{array}{l}\text { Consonant } \\
\text { Sequence }\end{array}$ & $\begin{array}{l}\text { FAD } \\
\text { DAS }\end{array}$ & $\begin{array}{r}3.17 \\
50.07\end{array}$ & $(1,15)$ & 11.74 & $*<0.01$ \\
\hline Stridents & $\begin{array}{l}\text { FAD } \\
\text { DAS }\end{array}$ & $\begin{array}{r}7.69 \\
42.54\end{array}$ & $(1,15)$ & 8.204 & $\div<0.01$ \\
\hline Velars & $\begin{array}{l}\text { FAD } \\
\text { DAS }\end{array}$ & $\begin{array}{r}4.08 \\
39.13\end{array}$ & $(1,15)$ & 8.918 & $*<0.01$ \\
\hline Liquid (1) & $\begin{array}{l}\text { FAD } \\
\text { DAS }\end{array}$ & $\begin{array}{l}14.36 \\
65.11\end{array}$ & $(1,15)$ & 9.748 & $*<0.01$ \\
\hline Glides & $\begin{array}{l}\text { FAD } \\
\text { DAS }\end{array}$ & $\begin{array}{r}3.89 \\
25.89\end{array}$ & $(1,15)$ & 5.305 & $*<0.04$ \\
\hline Assimilation & $\begin{array}{l}\text { FAD } \\
\text { DAS }\end{array}$ & $\begin{array}{l}0.67 \\
3.47\end{array}$ & $(1,15)$ & 8.432 & $\star<0.01$ \\
\hline
\end{tabular}


The null hypothesis for this study is rejected in that elementary school-age children diagnosed as presenting with moderate to severe FAD do demonstrate significant differences in properties and types of speech sound errors than children with DAS when assessed using a standardized phonological process test and analysis.

\section{DISCUSSION}

The data from the SYSTAT computer program software reveal a significant difference in the use of phonological processes between MAD children with DAS and those without DAS (FAD group). Three limiting factors must be kept in mind throughout this discussion: (a) the small number of subjects, (b) the age range, and (c) the screening measure, STDAS, used to divide the groups into DAS and FAD.

The results for the first research question indicated that the two groups differed significantly in average use of phonological processes. No literature is available for direct comparison. One consideration is the possible overidentification of subjects by the STDAS which may be influencing the data. On the other hand, if the STDAS has correctly identified those subjects with DAS, an explanation for the greater number of errors may simply be that with the motor impairment of the disorder of DAS, subjects produce more phonological process errors than subjects with FAD.

It is surprising that the DAS subjects demonstrated phonological patterning since the literature indicates that their errors are inconsistent, rather than being stable (Nicolosi, Harryman, \& Kresheck, 1983; Rosenbek \& Wertz, 1972). It could be, however, that 
the inconsistency in error production may inadvertantly increase the type of errors produced. On the other hand, the statistical significance of the data requires consideration.

To answer the second research question, the results indicate there is a significant difference in the use of several phonological processes by subjects with DAS as compared to use by those with FAD. The subjects with DAS were more deficient in the sound classes of strident, velar, liquid (1), glides, and assimilations than the subjects with FAD. It is important to point out that these same processes have been found to occur in both normal and disordered subjects (Stoe1-Gammon \& Dunn, 1985). Hodson and Paden (1981) found that unintelligible children used the same processes. Their study did not identify DAS in their subjects but chose to divide the group of subjects into intelligible and unintelligible groups. The five processes which Hodson and Paden determined to be indicators of "phonologically deviant systems" were cluster reduction, stridency deletion, stopping, and liquid deviation (Hodson \& Paden, 1981, p. 46). These processes were all present in the DAS subjects at a significantly greater frequency than in the FAD subjects.

The literature leads one to believe that for DAS there will be more errors in voicing (Yoss \& Darley, 1974a), metathesis (Morley, 1972), and assimilation (Yoss \& Darley, 1974a). In this study, no significant difference was found in the sound classes of voicing and metathesis. In contrast to Yoss and Darley's study, voicing errors were not found to be significantly different between the two groups. In addition, metathetic errors have been reported as characteristics 
of DAS by Aram and G1asson (1979), Edwards (1973), Morley (1972), and Rosenbek and Wertz (1972). In this study, there was no significant difference in the use of metathesis by the two groups. These differences between the results in the two studies can be attributed to several different reasons. The type of production elicitated, method of elicitation, length of the test word, degree of acquisition of the sound (Stoel-Gammon \& Dunn, 1985), word familiarity, and misidentification of subjects.

A quality which has frequently been given to DAS is resistance to treatment. We know that sounds are acquired over a period of time. A factor for the DAS group may be delayed development concomitant with motor deficits which prevent accurate, spontaneous production of speech sounds. The FAD group may be solely delayed, which may explain the difference in success of treatment.

It is too early to conclude that children with DAS use more phonological processes than children with FAD. More research is needed in FAD as well as DAS to define the two classifications, or to define a range of behaviors which encompass both disorders of MAD. Perhaps future research in phonological process use using large groups and various lengths of utterances will more precisely differentiate between the two groups. 


\section{CHAP TE R V}

\section{SUMMARY AND IMPLICATIONS}

\section{SUMMARY}

Focus has turned from emphasis on phonetic sound errors to phonologic rule systems in the study of articulation disorders. The current theory proposes that the phonological disorders which children experience are controlled by higher levels in the brain than those that control the motor functioning of the brain. The purpose of the present study was to compare the use of phonological processes by a group of school-age children with moderate to severe articulation disorders with developmental apraxia of speech to the phonological process used by those without developmental apraxia of speech.

The 18 subjects, ages 5.9 to 12.1 years, presenting with multiple articulation disorders, were chosen from the greater Portland, Oregon, metropolitan area. To qualify for the study, all subjects did not display mental retardation, hearing impairment, visual impairment, social-emotional impairment, multiple handicaps, or other impairments which could interfere with speech sound production. One group of ten children presented with DAS as determined by scores on the STDAS (Blakeley, 1980) and were classified as severe by scores on the AAPS-R (Fudala, 1982). The other group of eight subjects 
presented without DAS and were labeled FAD. Of the eight subjects, four were determined to have severe articulation disorders and the other four were determined to have moderate articulation disorder through AAPS-R. The APPS-R/CAPP (Hodson, 1986;1985) was administered and the percentage of use of phonological processes, phonological deviancy score, and average use of the ten basic phonological processes were calculated. Other processes which have been suggested by the literature to be indicative of DAS, e.g., voicing errors and metathesis, were also assessed and analyzed by hand.

A two-tailed t-test for independent means was used to determine if a statistically significant difference existed between the DAS and FAD subjects. A statistically significant difference ( $<.05$ ) was found between the two groups for average of phonological process use and phonological deviancy scores. In addition, use of the phonological processes of consonant sequence, stridents, velars, liquid (1), glides, and assimilations were found to be significantly different between the two groups with the DAS group using these processes more than the FAD group. A significant difference between the two groups was not found for syllable reduction, prevocalic singleton, postvocalic singleton, liquid ( $r$ ), nasals, metathesis and voicing errors. Although three factors, (a) the small number of subjects, (b) the age range, (c) the use of the STDAS to establish the DAS group, must be considered when drawing conclusions from the data, the results indicate a significant difference in the use of phonological processes by subjects with FAD and by those with DAS. The results suggest that more research is needed in the area of phonological 
process use by school-age children with MAD, with and without DAS. Treatment for children with DAS in addition to MAD may benefit from a phonological process approach in combination with a motor programing approach.

\section{IMPLICATIONS}

$\underline{\text { Research }}$

Two research implications are suggested by this study. One is a longitudinal study, using a large group of subjects and collecting data including case histories, language samples, observations, and records of the course of treatment, as well as the APP-R/CAPP. Case histories should include information on swallowing and feeding problems as well as early motor development. The objects from the APP-R could be used for the language sample which should be taped with the highest quality tape recorder possible. A series of assessments using the above instruments could be completed annually or semi-annually over a period of years encompassing the developmental years through age 12 , as long as the subject continues to demonstrate MAD.

Another research implication would be a treatment study combining motor and phonological approaches. Using three groups of moderate and severe MAD subjects, one group could be treated using a motor approach, another using a phonological approach, and the third group using a combination of phonological and motor approaches. A large number of subjects would be needed for the study to be significant. 
Clinical

One clinical implication raised by this study is the possible need to assess children with moderate and severe articulation disorders using a phonological process approach whether or not they are diagnosed as DAS. This approach may provide new information for the clinician about the child's productions and provide information for a more appropriate treatment. It has been proposed that motor impairments and phonological process impairment occur at different levels in the brain. Distinct differences in the use of phonological processes were demonstrated in this study between the MAD subjects with DAS and those with FAD. These differences may indicate that the children with DAS may have both a phonological and motor impairment, or that the subjects in this study are inaccurately identified as having DAS. A combination motor-phonological approach may produce better results for intervention, or it may not.

The results of this study raises more questions than it answers. The phonological process approach is not being used by all clinicians, and before it can be recommended that all clinicians use a phonological process approach to assess children with suspected DAS, more research is necessary. 


\section{REFE RENCES}

Abbs, J.H., and Rosenbek, J.C. (1986). Some motor control perspectives on apraxia of speech and dysarthria. In J.M. Costello and A.L. Holland (Eds.), Handbook of speech and language disorders (pp. 371-408). San Diego, CA: College Hill Press.

Aram, D.M, and Glasson, C. (1979). Developmental apraxia of speech. Paper presented at the annual convention of the American SpeechLanguage-Hearing Association, Atlanta, GA.

Bernthal, J.E., and Bankson, N.W. (1988). Articulation disorders

(2nd ed.). Englewood Cliffs, NJ: Prentice-Hall.

Blakeley, R.W. (1980). Screening test of developmental apraxia of speech. Tigard, OR: C.C. Publications.

Blakeley, R.W. (1983). Treatment of developmental apraxia of speech. In W.H. Perkins (Ed.), Dysarthria and apraxia (Pp. 25-33). NY: Thieme-stratton.

Chappe 11, G.E. (1973).. Childhood verbal apraxia and its treatment. Journal of Speech and Hearing Research, 16, 362-368.

Compton, A.J. (1970). Generative studies of children's phonological disorders. Journal of Speech and Hearing Disorders, 35, 315-339.

Crary, M.A. (1981). Phonological process analys is of developmental verbal dyspraxia: A descriptive study. Paper presented at the annual convention of the American Speech-Language-Hearing Association, Los Angeles, CA.

Crary, M.A. (1982). Developmental verbal dyspraxia: A phonological research perspective. Paper presented at the Annual Convention of the American Speech-Language-Hearing Association, Toronto, Canada.

Creaghead, N.A., and Newman, P.W. (1989). Articulatory phonetics and phonology. In N.A Creaghead, P.W. Newman, and W.A. Secord, Assessment and remediation of articulatory and phonological disorders (2nd ed.). Columbus, OH: Merrill.

Dunn, C., and Davis, B.L. (1983). Phonological process occurrence in phonologically disordered children. Applied Psycholinguists, 4 , $187-207$. 
Dunn, L.M., and Dunn, L.M. (1981). Peabody picture vocabulary test revised. Circle Pines, MN: American Guidance Service.

Edwards, M. (1973). Developmental verbal dyspraxia. British Journal of Disorders of Communication, $8,64-70$.

Fudala, J. (1982). Arizona articulation proficiency scale: Revised, ( 9 th ed.), Los Angeles, CA: Western Psychological Services.

Goldman, R., and Fristoe, M. (1986). Test of articulation. Circle Pines, MN: American Guidance Service.

Guyette, T.W., and Diedrich, W.M. (1981). A critical review of developmental apraxia of speech. In N.J. Lass (Ed.), Speech and language: Advances in basic research and practice (Vo1. 5), NY: Academic Press.

Hall, P.K. (1989). The occurrence of developmental apraxia of speech in a mild articulation disorder: A case study. Journal of Communication Disorders, 22, 265-276.

Haynes, S. (1985). Developmental apraxia of speech: Symptoms and treatment. In D.F. Johns (Ed.), Clinical management of neurogenic communication disorders. Boston, MS: College Hill Press.

Hodson, B.W. (1985). Computer analysis of phonological processes. Stonington, IL: Phono Comp.

Hodson, B.W. (1986). The assessment of phonological processes-revised. Danville, IL: Interstate.

Hodson, B.W., and Paden, E.P. (1981). Phonological processes which characterize unintelligible and intelligible speech in early childhood. Journal of Speech and Hearing Disorders, 46, 369-373.

Hodson, B.W., and Paden, E.P. (1983). Targeting intelligible speech. Boston, MS: College-Hill Press.

Ingram, D. (1981). Procedures for the phonological analysis of children's language. Baltimore, MD: University Park Press.

Ingram, D. (1982). Assessment of phonological disorders in children: The state of the art. In M.A. Crary (Ed.), Phonological intervention (Pp. 1-12). San Diego: CA: College-Hill.

Jaffe, M.B. (1984). Neurological impairment of speech production: Assessment and treatment. In J.M. Coste1lo (Ed.), Speech disorders in children (pp. 259-266). San Diego, CA: CollegeHill Press. 
Kahn, L., and Lewis, N. (1986). Phonological analysis. Circle Pines, MN: American Guidance Service.

Luce, P., and Pisoni, D.B. (1987). Speech perception. In H. Winitz (Ed.), Human communication and its disorders, a review 1987 (pp. 15-19). Norwood, NJ: Ablex.

McClumpha, S.L., and Logue, R.D. (1972, October). Approaches to children with motor programing disorders of speech. Paper presented at the annual convention of the American Speech and Hearing Association, San Francisco, CA.

McDona1d, E.T. (1964). Articulation testing and treatment: A sensory-motor approach. Pittsburg, PA: Stanwick House.

McReynolds, L.V. (1986). Functional articulation disorders. In G.H. Shames and E.H. Wiig (Eds.), Human communication disorders (PP. 139-182). Columbus, OH: Charles E. Merrill.

Mor ley, M.E. (1972). Development and disorders of speech in childhood ( $3 r d$ ed.). London: E. and S. Livingstone.

Morley, M.E., and Fox, J. (1969). Disorders of articulation: Theory and therapy. Journa 1 of Communication Disorders, 4, 151-164.

Nelson, D.C. (personal communication, September 10, 1989).

Newcommer, P.L., and Hammi11, D.D. (1982). Test of language development - intermediate. Austin, TX: Pro-Ed.

Newcommer, P.L., and Hammi11, D.D. (1982). Test of language development - primary. Austin, TX: Pro-Ed.

Nicolosi, I., Harryman, E., and Kresheck, J. (1983). Terminology of communication disorders (2nd ed.). Baltimore, MD: Williams $\&$ Wilkins.

Preisser, D.A., Hodson, B.W., and Paden, E.P. (1988). Developmental phonology: 18-29 months. Journal of Speech and Hearing Disorders, 53, 125-130.

Prichard, C.L., Tekieli, M.E., and Kozup, J.M. (1979). Developmental apraxia: Diagnostic consideration. Journal of Communication Disorders, $12,337-348$.

Rosenbek, J.C. (1982). Treating apraxia of speech in children and adults. Short course presented at the 4 th annual Three Rivers Conference of Communicative Disorders, Pittsburgh, PA. 
Rosenbek, J.C., Hansen, R., Baughman, C.H., and Lemme, M. (1974). Treatment of developmental apraxia of speech: A case study. Language, Speech, and Hearing Services in Schools, 5, 13-22.

Rosenbek, J.C., and Wertz, R.T. (1972). A review of 50 cases of developmental apraxia of speech. Language, Speech, and Hearing Services in the Schools, 3 , 23-33.

Shriberg, L.D., and Kwiatkowski, J. (1980). Natural process analysis (NPA): A procedure for phonological analysis of continuous speech samples. NY: John Wiley \& Sons.

Smartt, J., LaLance, L., Gray, J., and Hibbett, P. (1976). Developmental apraxia of speech: A Tennessee Speech and Hearing Association subcommittee report. Journal of the Tennessee Speech and Hearing Association, 20, 21-3l.

Stoel-Gammon, C., and Dunn, C. (1985). Normel and disordered phonology in children. Baltimore, MD: University Park Press.

Van Riper, C., and Irwin, J.U. (1958). Voice and articulation. Englewood Cliffs, NJ: Prentice-Hall.

Weiner, F.F. (1979). Phonological process analysis. Baltimore, MD: University Park Press.

Weiss, C.E., Gordon, M.E., and Lillywhite, H.S. (1987). Clinical management of articulatory and phonologic disorders (2nd ed.). Baltimore, MD: Williams \& Wilkins.

Williams, R., Ingham, R.J., and Rosenthal, J. (1981). A further analysis for development apraxia of speech in children with defective articulation. Journal of Speech and Hearing Research, 24, 496-505.

Winitiz, H. (1984). Auditory considerations in articulation training. In H. Winitz (Ed.), Treating articulation disorders: For clinicians by clinicians. Baltimore, MD: University Park Press.

Wilkinson, L. (1988). SYSTAT: The system for statistics. Evanston, IL: SYSTAT, Inc.

Woodward, G. (1990). Identification of dyspraxic characteristics in children with moderate to severe articulation disorders. Unpublished master's thesis, Portland State University, Portland, OR.

Yoss, K.A., and Darley, L.F. (1974a). Developmental apraxia of speech in children with defective articulation. Journal of Speech and Hearing Research, 17, 386-398.

Yoss, R.A., and Darley, L.F. (1974b). Therapy in developmental apraxia of speech. Language, Speech, and Hearing Services in the Schools, $1,23-3 \bar{l}$. 
APPENDIX A

DEFINITIONS OF THE PHONOLOGICAL PROCESSES USED IN THE ASSESSMENT OF PHONOLOGICAL PROCESSES

(Hodson, 1986) 
DEFINITIONS OF THE PHONOLOGICAL PROCESSES USED IN THE ASSESSMENT

OF PHONOLOGICAL PROCESSES (Hodson, 1986)

\section{OMISSIONS}

Consonant Sequence Reduction: omission of a consonant from a sequence of consonants (e.g., /tring/ for "string").

Syllable Reduction: Deletion of a syllable nucleus in a multisyllabic word (e.g., /ba/ for "bottle").

Prevocalic Singleton Consonant Omission: deletion of a singleton consonant which initiates a syllable (e.g., /i/ for "baby").

Postvocalic Singleton Consonant Omission: deletion of a singleton consonant which terminates a syllable (e.g., /wa/ for "watch").

\section{CLASS DEFICIENCIES}

Glide: substitution for or omission of $/ \mathrm{w} /$ or $/ \mathrm{j} /(\mathrm{e} . \mathrm{g} \cdot, / \mathrm{kin} /$ for "queen"; /1010/ for "yoyo."

Liquid (1): substitution for or omission of $/ 1 /(\mathrm{e} . g .$, /gwub/ for "glove"; /guv/ for "glove."

Liquid (r): substitution for or omission of $/ r /(e . g \cdot, / w a b b i t /$ for "rabbit"; /kel nz/ for "crayons."

Nasals: substitution for or omission of $/ \mathrm{m} /, / \mathrm{n} /, / \mathrm{n} /(\mathrm{e} . \mathrm{g} ., \mathrm{pu} /$ for "spoon"; /douz/ for "nose."

Strident: substitution for or omission of $/ \mathrm{s} /, / \mathrm{z} /, / \mathrm{S} /(\mathrm{sh}), / \mathrm{z}^{\prime}$ $(z h), / t g /(c h), / d z /(J), / f, v /$ (e.g., /pels/ for "paige"; /tanta/ for "Santa."

Velar: substitution for or omission of $/ \mathrm{k} /$ or $/ g /(\mathrm{e} . \mathrm{g} ., / \mathrm{dum} /$ for "gum"; / tat/ for "cat"; /wuu/ for "glove."

\section{PHONEMIC SUBSTITUTIONS}

Metathesis: transposition of phonemes /baksit/ for "baskit."

Deaffrication: replacement of an affricate with a stop or continuant /ter/for "chair."

Assimilation: replacement of a phoneme with one that is like another phoneme in the word /brosit/ for baskit;/lello/ for "yellow."

Voicing Alterations: change of voicing on an individual phoneme / kin/ for "green." 
APPENDIX B

CONSENT FORM 
CONSENT FORM

\section{Dear Parent:}

We are presently graduate students in the Speech and Hearing Sciences Program at Portland State University. We are investigating how children in public schools who have problems saying certain sounds perform on the Screening Test for Developmental Apraxia of Speech and The Assessment of Phonological Processes. We would appreciate your permission to include your child in this project.

The testing will involve the instruments mentioned above, a hearing screening, administration of articulation tests, and expressive and receptive language tests. Your child will be identifying pictures and objects, repeating words, and imitating oral movements. The testing procedures will be carried out in one session taking approximately one hour of your child's time to complete.

Your child's participation in this study will present no physical or psychological risks. All data obtained during the course of study will remain confidential. Published data will not reveal the name of your child.

If you decide to allow your child to participate in this study, please fill out the appropriate portion of this form. Pleas return your reply to your child's classroom teacher as soon as possible. If you choose to allow your child to participate, you are free to withdraw him/her from the study at any time without affecting services provided at his/her school or from Portland State University. This study will benefit children with severe articulation disorders by providing new information to the speech-language pathologists working with them.

I have read and understand the above statements, and I agree to let my child, , participate in this study.

If you experience problems that are the result of your participation in this study, please contact the secretary of the Human Subjects Research Review Comittee, Office of Grants and Contracts, 303 Cramer Ha11, Portland State University, 725-3417. 
APPENDIX C

APP-R TEST FORM 
48

THE ASSESSMENT OF PHONOLOGICAL PROCESSES - ReVised Barbara Williams Godson

Name Birthrate Date Examiner

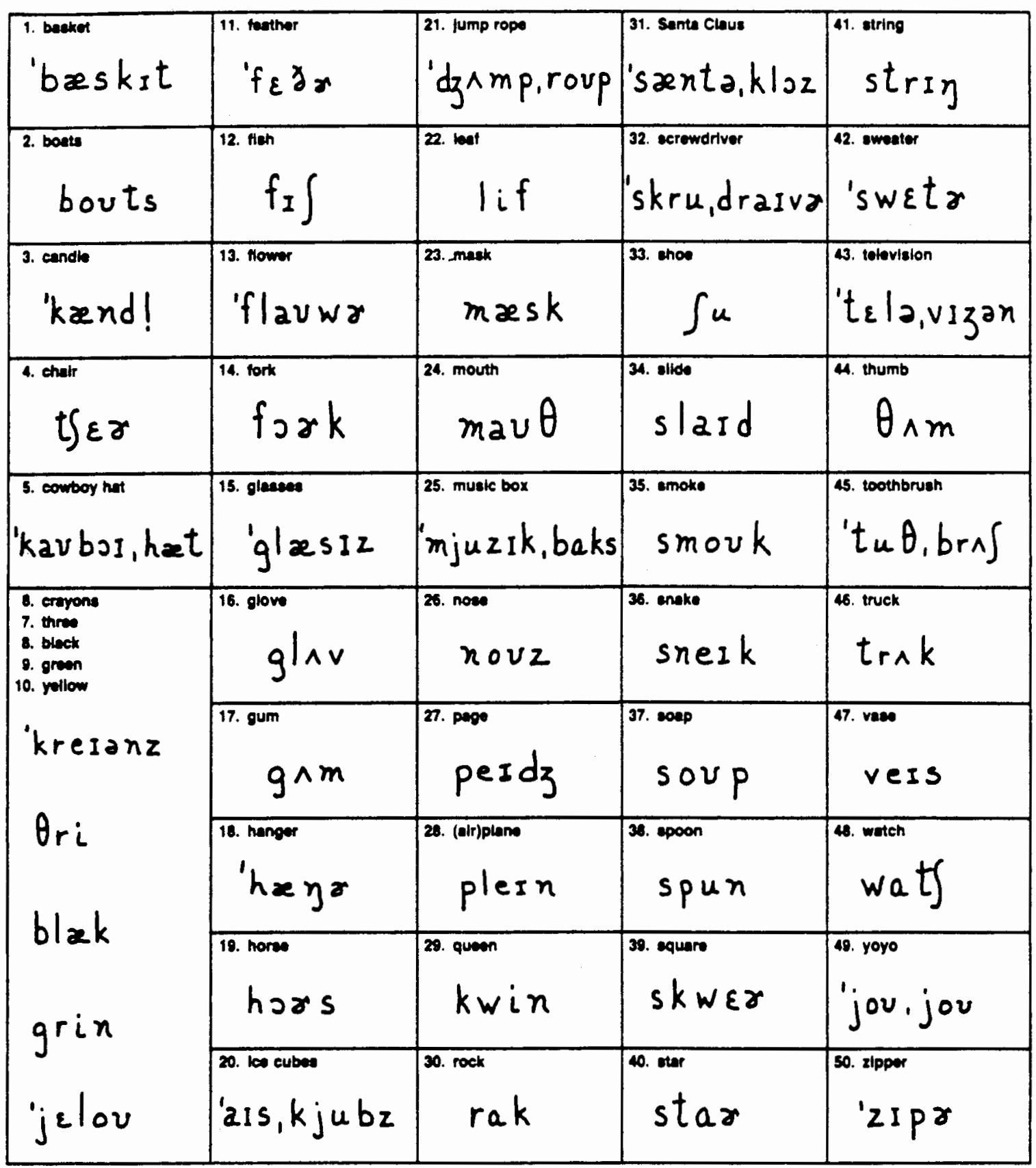

Copyright @1986 by PRO-ED, Inc

Additional copies of this form (Order No. 3402) available
tram PRO. ED. Inc. BT00 Shod Creek Boulevard. Austin. Tox as 78758 


\section{APPENDIX D}

APP-R ANALYSIS FORM 


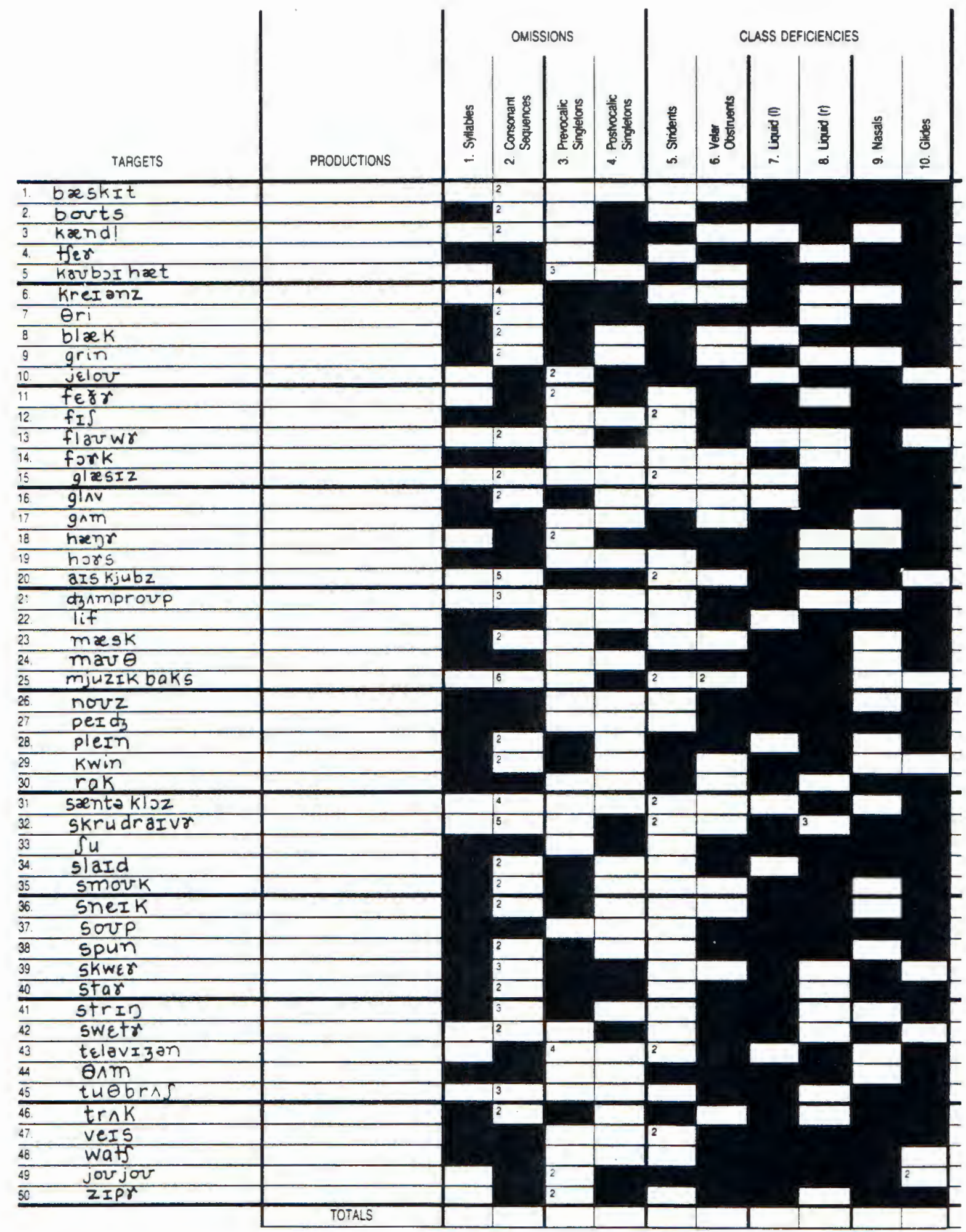




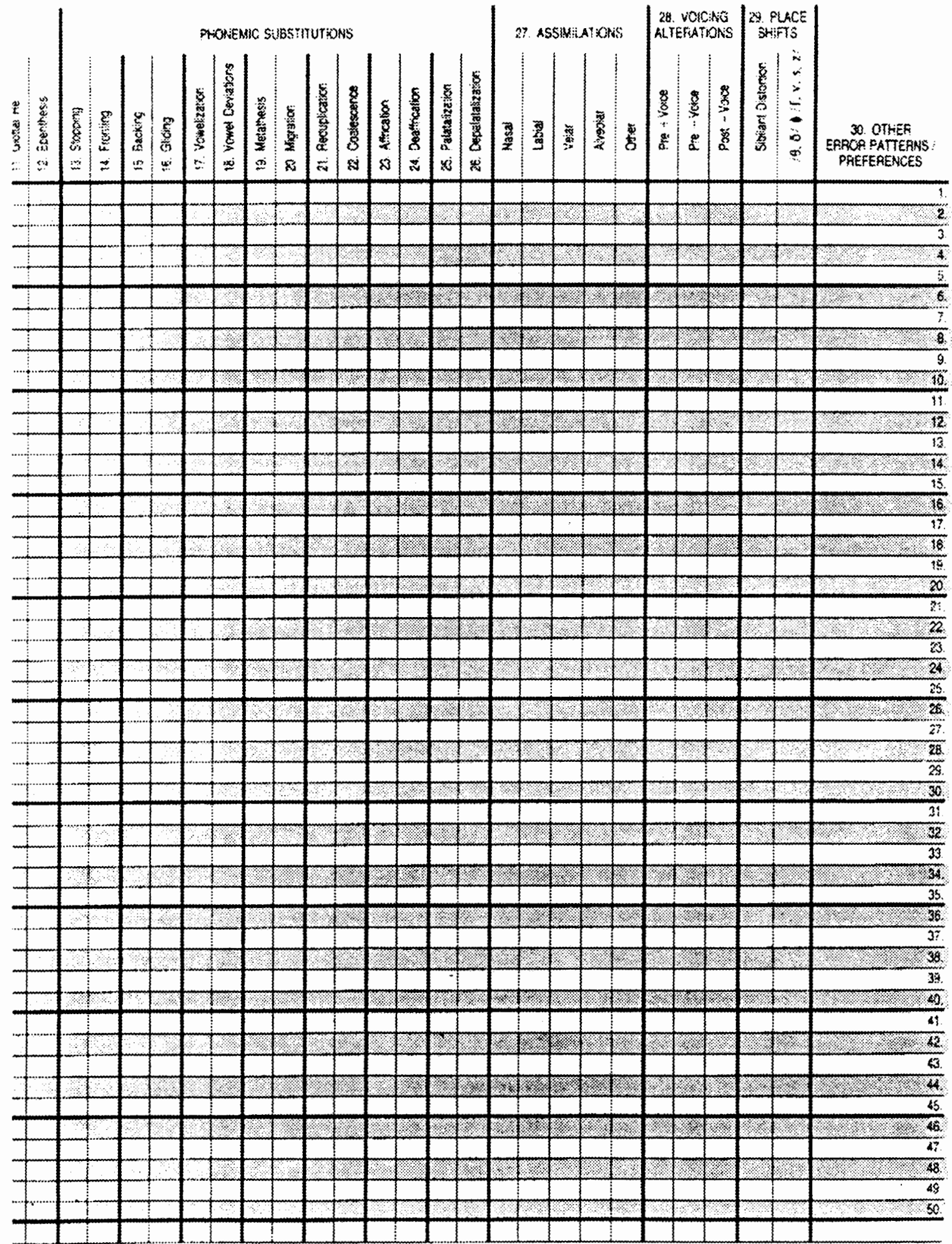


APPENDIX E

\section{CAPP FORM}


CAPP FORM

$\begin{array}{ll}\text { Name of Client: } & \mathrm{A} \\ \text { Date of Birth: } & 7 / 21 / 84 \\ \text { Date of Phonological: } & 5 / 21 / 90 \\ \text { Age in Years: } & 5 \\ \text { Exminaer's Name: } & \mathrm{K} \\ \text { Diagnostic Information: } & \end{array}$

Phonological Analysis Summary

Pattern Deviations

Syllable Reduction

Prevocalic Singletons

Postvocalic Singletons

Consonant Sequences

Stridents

Velars

Liquid (1)

Liquid ( $r$ )

Nas als

Glides
Percentage of Occurrence
0
0
0
33
42
18
64
90
5
20

Average of Phonological Processes: 27

Phonological Deviancy Score:

Severity Interva 1: Moderate

GOAL: To increase intelligibility by facilitating emergence of the following phonological patterns:

Stridents

Liquid (1)

Liquid ( $r$ ) 